\title{
Longterm effects of palliative local treatment of incurable metastatic lesions in colorectal cancer patients
}

\author{
Qiong Yang ${ }^{1,2,3,4, *}$, Fangxin Liao, ${ }^{1,3,4, *}$, Yuanyuan Huang ${ }^{1,3,4}$, Chang Jiang ${ }^{1,3,4}$, \\ Shousheng Liu' ${ }^{1,3,4}$, Wenzhuo He , $^{1,3,4}$, Pengfei Kong ${ }^{1,3,4}$, Bei Zhang ${ }^{1,3,4}$ and Liangping \\ Xia ${ }^{1,3,4}$ \\ ${ }^{1}$ VIP Region, Sun Yat-sen University Cancer Center, Guangzhou, Guangdong, P.R. China \\ 2 Department of Oncology, Sun Yat-sen Memorial Hospital, Guangzhou, Guangdong, P.R. China \\ ${ }^{3}$ State Key Laboratory of Oncology in South China, Sun Yat-sen University Cancer Center, Guangzhou, Guangdong, P.R. \\ China \\ ${ }^{4}$ Collaborative Innovation Center for Cancer Medicine, Guangzhou, Guangdong, P.R. China \\ * These authors have contributed equally to this paper \\ Correspondence to: Liangping Xia, email: xialiangping@163.com \\ Bei Zhang, email: zhangbei@sysucc.org.cn \\ Keywords: metastatic colorectal carcinoma, palliative local treatment, chemotherapy, propensity score matching, prognosis \\ Received: November 11,2015 Accepted: February 24, $2016 \quad$ Published: March 15, 2016
}

\section{ABSTRACT}

We assessed the value of palliative local treatment of incurable metastatic lesions in colorectal cancer patients. Consecutive patients with metastatic colorectal cancer treated between 2003 and 2014 were retrospectively reviewed. Propensity score matching was used to create comparable palliative local treatment and chemotherapy alone groups ( $n=272$ in each group). The primary endpoint was overall survival, which was calculated using Kaplan-Meier survival analyses. Factors possibly influencing survival were evaluated by univariate and subsequently by multivariate analyses. Palliative local treatment prolonged survival as compared with chemotherapy alone ( 38.73 vs. 19.8 months, $p<0.01$ ). Univariate and subsequent multivariate analyses showed that primary stage IV at initial diagnosis; high CA199 level and LDH at the time of diagnosis were independent factors for a poor prognosis. Palliative local treatment improved survival better than chemotherapy alone in patients with 0,1 , 2 , or 3 of the prognostic factors $(p<0.01)$. Patients administered treatment for pulmonary metastases survived longer than those treated for metastases elsewhere ( 56.77 vs. 35.43 months, $p=0.01$ ). Surgical treatment provided marginally longer survival than non-surgical treatment (44.87 vs. 35.43 months, $p=0.05)$. These findings suggest palliative local treatment has survival benefit for selected patients with incurable metastatic colorectal cancer.

\section{INTRODUCTION}

Approximately $40 \%-50 \%$ of newly diagnosed colorectal cancer (CRC) patients have one or more metastatic lesions. Among those patients, only 33\% have a chance for complete resection of the metastatic and primary lesions [1]. Complete resection, either initially or after chemotherapy, effectively improves overall survival (OS) [2-4]. By contrast, patients with incurable metastatic lesions have little chance of surviving over 5 years. For those patients, standard chemotherapy with monoclonal antibodies provides only 10.8 months of progression- free survival (PFS) and 29.9 months of OS [5, 6]. It is, therefore, necessary to explore new approaches to treat these patients.

The evolution of local treatment with curative intention reflects the fact that active surgery plays an important role in treatment of metastatic (m) CRC. For example, hepatic metastasectomy for $\mathrm{mCRC}$ was regarded as providing no chance for a cure two decades ago. Later, however, it was demonstrated that this procedure brings a survival benefit as long as patients the patient has fewer than four metastatic lesions with diameters less than 3 $\mathrm{cm}$ and with a $1 \mathrm{~cm}$ clean surgical margin. And now, the 
requirements for this procedure have been simplified further to complete resection of hepatic lesions as long as adequate liver function is preserved after the operation [7-11].

Palliative local treatment as part of a treatment plan to eradicate some of the metastatic lesions has seldom explored in incurable $\mathrm{mCRC}$ except in response to an emergency, such as intestinal obstruction, bleeding or perforation. It was reported that palliative local treatment didn't improve long-term outcome for patients with widespread disease [12]. Nonetheless, recent studies suggest survival is improved in mCRC patients who undergo local treatment of metastatic lesions, as compared to historical controls administered chemotherapy alone [13-15]. But these studies have limitations, including a small number of patients and no control group or data from subgroup analysis. Consequently, the value of palliative local treatment for incurable $\mathrm{mCRC}$ remains unclear.

The aim of the present study, therefore, was to assess long-term survival in $\mathrm{mCRC}$ patients receiving palliative local treatment of incurable metastatic lesions and the factors affecting the outcome of this procedure.

\section{RESULTS}

As shown in Figure 1, 1174 consecutive mCRC patients were enrolled while $62(5.3 \%)$ patients who received curative local treatment were excluded. Ultimately, 290 (24.7\%) patients initially entered the palliative local treatment group, and 822 (70\%) entered the chemotherapy alone group. Due to the imbalance in baseline data between the two groups, propensity score matching was used to minimize selection bias. The variables used for matching included age, sex, primary location, stage at first diagnosis, status of K-RAS, and the number of metastatic lesions. After propensity score matching, 544 patients were included, with 272 in each group. A median of 2 lines of chemotherapy were used in both the palliative local treatment (range 0-8) and chemotherapy alone (range 0-6) groups. Additional details of patients' characteristics are summarized in Table 1.

\section{Survival benefit from palliative local treatment}

By the last follow-up (median 53.3 months, range 1.5-142.0 months), tumors had recurred in 199 (73.2\%) of the 272 locally treated patients. Among those, 61 (30.7\%) were recurrences of previously treated lesions and 138 $(69.3 \%)$ were new lesions, with or without recurrence of previously treated lesions. Eighty-six (43.2\%) of the recurrences were treated with two or more repeats of palliative local treatment. Among the patients in the palliative local treatment group, $163(59.9 \%)$ had died by the last follow-up and $109(40.1 \%)$ were alive. In the chemotherapy alone group, $184(67.6 \%)$ patients had died by the last follow-up and $88(32.4 \%)$ were alive. The median OS in palliative local treatment and chemotherapy alone were 38.73 months (95\%CI 34.93-42.54) and 19.8 months (95\%CI 18.06-21.54), respectively $(P<0.01)$. The corresponding 2-, 3- and 5-year survival rates were $78 \%, 52.2 \%$ and $26.2 \%$, respectively, in palliative local treatment group and $37 \%, 22 \%$ and $11 \%$, respectively, in the chemotherapy alone group, $(P<0.01)$ (Figure 2).

\section{Who would be benefit from palliative local treatment?}

There were 12 factors that could potentially influence OS, and 7 were significantly associated with outcome in a univariate analysis (Table 2). These included the primary tumor site $(P=0.02)$, stage at the first diagnosis $(P<0.01)$, tumor pathological grading $(\mathrm{P}$ $=0.004)$, lines of palliative chemotherapy $(P<0.01)$, metastatic sites $(P<0.01)$, level of CEA $(P=0.01)$, CA199 $(P<0.01)$, and $\operatorname{LDH}(P<0.01)$ before all palliative treatment. Multivariate analysis (Table 3 ) showed that stage IV at the first diagnosis $(P=0.02)$, a pre-treatment CA199 level $\geq 35 \mathrm{U} / \mathrm{ml}(P<0.01)$ and a pre-treatment $\mathrm{LDH}$ level $\geq 245 \mathrm{U} / \mathrm{L}(P=0.003)$ were independent prognostic factors associated with poor OS. The 5-year survival rate in patients positive for $0,1,2$, or 3 of those prognostic factors was $34.5 \%, 20.0 \%, 6.5 \%$, and $0 \%$, respectively $(P$ $<0.01)$. Compared with chemotherapy alone, palliative local treatment improved survival whether the patient exhibited $0,1,2$, or 3 of the prognostic factors $(P<0.01$, details shown in Table 4).

\section{When is the best time to administer palliative local treatment?}

Of the 272 patients administered palliative local treatment, 77 received it before palliative systemic chemotherapy, 99 received it during first-line chemotherapy, 40 after first-line chemotherapy but before the second-line chemotherapy, 17 during the second-line chemotherapy, and 39 after the second-line chemotherapy. The timing of the administration of palliative local treatment had no effect on survival benefit $(P=0.74$, Figure 3 ). In addition, whether there was a response to chemotherapy before local treatment also had no effect on survival benefit $(P=0.71$, Figure 4$)$.

\section{What is the most effective type of palliative local treatment?}

Of those administered palliative local treatment, 120 were treated surgically to remove metastases (metastasectomy), while 152 were non-surgically. The nonsurgical treatments included RFA, PMCT, radioactive 
Table 1:Baseline demographics and clinical characteristicsof mCRCpatients before and after propensity score matching

\begin{tabular}{|c|c|c|c|c|c|c|}
\hline \multirow[b]{2}{*}{ Characteristics } & \multicolumn{2}{|c|}{ Before matching (N) } & \multirow[b]{2}{*}{$P$} & \multicolumn{2}{|c|}{ After matching (N) } & \multirow[b]{2}{*}{$P$} \\
\hline & Local treatment & Control & & $\begin{array}{l}\text { Local } \\
\text { treatment }\end{array}$ & Control & \\
\hline Total & 290 & 822 & & 272 & 272 & \\
\hline Sex & & & 0.50 & & & 0.93 \\
\hline Men & 182 & 534 & & 173 & 174 & \\
\hline Women & 108 & 288 & & 99 & 98 & \\
\hline Age (years) & & & 0.06 & & & 0.29 \\
\hline Median (range) & $53(13-80)$ & $55(10-89)$ & & $53(13-80)$ & $53(10-80)$ & \\
\hline$<65$ & 236 & 624 & & 222 & 212 & \\
\hline$\geq 65$ & 54 & 198 & & 50 & 60 & \\
\hline ECOG PS & & & $<0.01$ & & & 0.87 \\
\hline 0 & 60 & 100 & & 59 & 56 & \\
\hline 1 & 220 & 678 & & 206 & 205 & \\
\hline 2 & 10 & 44 & & 9 & 11 & \\
\hline Primary tumor site & & & $<0.01$ & & & 0.06 \\
\hline Colon & 172 & 581 & & 164 & 185 & \\
\hline Left-semicolon & 108 & 320 & & 104 & 119 & \\
\hline Right-semicolon & 64 & 261 & & 60 & 66 & \\
\hline Rectum & 118 & 241 & & 108 & 87 & \\
\hline Stage at initial diagnosis & & & $<0.01$ & & & 0.22 \\
\hline Metastatic disease & 172 & 607 & & 163 & 177 & \\
\hline Primary site resected & 153 & 277 & & 145 & 119 & \\
\hline Primary site unresected & 19 & 230 & & 18 & 58 & \\
\hline Non-metastatic disease & 118 & 215 & 0.03 & 109 & 95 & 0.42 \\
\hline $\mathrm{I}$ & 3 & 3 & & 3 & 1 & \\
\hline II & 44 & 56 & & 41 & 30 & \\
\hline III & 71 & 156 & & 65 & 64 & \\
\hline Tumor differentiation (grade) & & & 0.02 & & & 0.41 \\
\hline Well & 15 & 33 & & 14 & 13 & \\
\hline Moderate & 175 & 412 & & 175 & 183 & \\
\hline Poor & 47 & 174 & & 47 & 52 & \\
\hline Mucinous adenocarcinoma & 36 & 127 & & 36 & 24 & \\
\hline Unknown & 17 & 76 & & 0 & 0 & \\
\hline KRAS status & & & $<0.01$ & & & 0.18 \\
\hline Wild type & 92 & 147 & & 90 & 111 & \\
\hline Mutation type & 25 & 60 & & 24 & 21 & \\
\hline Unknown & 173 & 615 & & 158 & 140 & \\
\hline Number of metastatic lesions & & & $<0.01$ & & & 0.06 \\
\hline 1 & 23 & 16 & & 20 & 13 & \\
\hline 2 & 20 & 10 & & 15 & 10 & \\
\hline 3 & 18 & 3 & & 10 & 3 & \\
\hline 4 & 8 & 3 & & 7 & 3 & \\
\hline$\geq 5$ & 221 & 790 & & 220 & 243 & \\
\hline Metastatic sites & & & 0.01 & & & 0.32 \\
\hline Liver & 76 & 254 & & 72 & 85 & \\
\hline Lung & 16 & 57 & & 15 & 22 & \\
\hline Liver and lung & 38 & 58 & & 26 & 23 & \\
\hline Other & 160 & 453 & & 159 & 142 & \\
\hline Line of chemotherapy & & & $<0.01$ & & & 0.09 \\
\hline
\end{tabular}




\begin{tabular}{|l|l|l|l|l|l|l|}
\hline 1 & 285 & 796 & & 267 & 268 & \\
\hline 2 & 206 & 425 & & 201 & 168 & \\
\hline 3 & 112 & 155 & & 110 & 76 & \\
\hline$\geq 4$ & 48 & 61 & & 46 & 31 & \\
\hline Systematic chemotherapy & & & 0.11 & & & 1.00 \\
\hline Received & 286 & 796 & & 268 & 268 & \\
\hline Not received & 4 & 26 & & 4 & 4 & \\
\hline Target drugs & & & $<0.01$ & & & 0.42 \\
\hline Anti-VEGF / Anti-EGFR & 145 & 277 & & 140 & 133 & \\
\hline Neither & 145 & 545 & & 32 & 39 & \\
\hline Pre-treatment CEA (ng/ml) & $350.35 \pm 90.1$ & $451.65 \pm 69.24$ & 0.48 & $359.91 \pm 94.1$ & $427.13 \pm 115.06$ & 0.66 \\
\hline Pre-treatment CA 199 (U/ml) & $443.94 \pm 127.34$ & $1361.75 \pm 205.52$ & $<0.01$ & $427.13 \pm 115.06$ & $795.97 \pm 169.71$ & 0.11 \\
\hline Pre-treatment LDH (U/L) & $270.20 \pm 20.74$ & $368.08 \pm 18.32$ & $<0.01$ & $270.38 \pm 21.49$ & $332.09 \pm 24.14$ & 0.06 \\
\hline
\end{tabular}

Abbreviations: PS, performance status; VEGF,vascular endothelial growth factor; EGFR,epidermal growth factor receptor; CEA,carcinoembryonic antigen;CA199, carbohydrate antigen 199; LDH,lactate dehydrogenase.

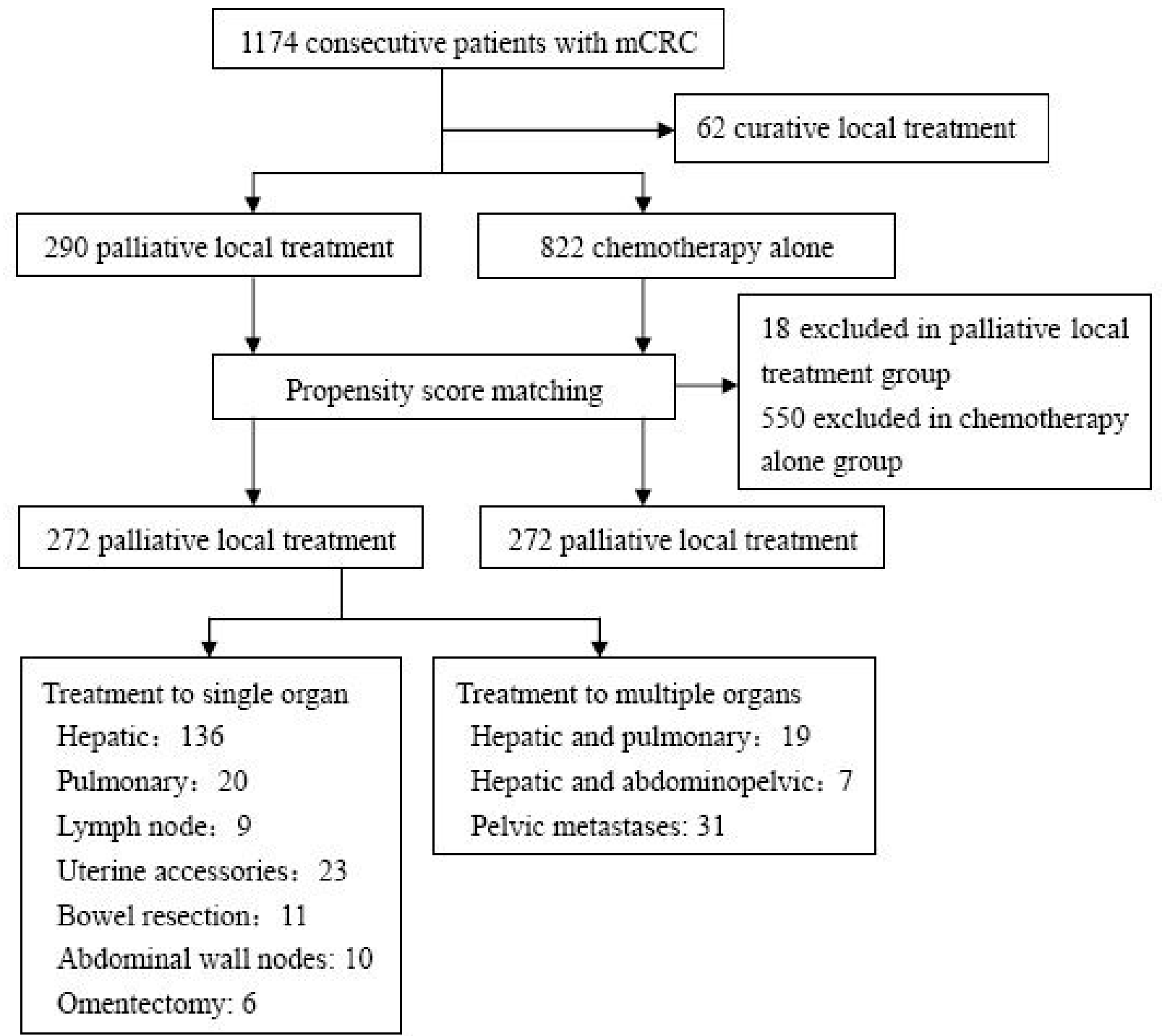

Figure 1: Flow chart of patient's inclusion and overview of palliative local treatment. The variables used for matching included age, sex, primary location, stage at the first diagnosis, K-RAS status, and the number of metastatic lesions. After propensity score matching, the patients' baseline characteristics were balanced between palliative local treatment group and chemotherapy alone group. 
Table 2: Predictors of overall survival based on univariate analysis

\begin{tabular}{|c|c|c|c|c|}
\hline Factors & Number of patients & Median OS(95\%CI) (months) & 5-year SR (\%) & $P$ \\
\hline Sex & & & & 0.48 \\
\hline Men & 173 & $35.43(30.83-40.04)$ & $32.4 \%$ & \\
\hline Women & 99 & $39.70(31.06-48.34)$ & $17.7 \%$ & \\
\hline Age (years) & & & & 0.75 \\
\hline$<65$ & 222 & $39.53(33.41-45.66)$ & $27.7 \%$ & \\
\hline$\geq 65$ & 50 & $34.77(28.04-41.49)$ & $19.8 \%$ & \\
\hline Primary tumor site & & & & 0.02 \\
\hline Colon & 164 & $35.43(31.38-39.49)$ & $22.3 \%$ & \\
\hline Rectum & 108 & $42.67(37.00-48.34)$ & $31.7 \%$ & \\
\hline Stage at initial diagnosis & & & & $<0.01$ \\
\hline Metastatic disease & 163 & $35.43(31.25-39.62)$ & $17.1 \%$ & \\
\hline Non-metastatic disease & 109 & $46.67(38.03-55.31)$ & $39.8 \%$ & \\
\hline Tumor differentiation (grade) & & & & 0.004 \\
\hline Well & 14 & $72.60(55.87-89.33)$ & $80.8 \%$ & \\
\hline Moderate & 175 & $39.50(32.18-46.82)$ & $26.1 \%$ & \\
\hline Poor & 47 & $33.40(28.81-38.00)$ & $12.5 \%$ & \\
\hline Mucinous adenocarcinoma & 36 & $36.03(23.04-49.03)$ & $20.7 \%$ & \\
\hline KRAS status & & & & 0.37 \\
\hline Wild type & 90 & $46.67(39.72-53.62)$ & $38.7 \%$ & \\
\hline Mutation type & 24 & $35.13(29.74-40.53)$ & & \\
\hline Unknown & 158 & $36.03(31.42-40.64)$ & $21.6 \%$ & \\
\hline Number of metastases & & & & 0.15 \\
\hline 1 & 20 & $40.60(31.19-50.16)$ & $35.2 \%$ & \\
\hline 2 & 15 & $34.77(25.86-43.66)$ & $15.4 \%$ & \\
\hline 3 & 10 & $64.43(27.43-101.44)$ & $53.3 \%$ & \\
\hline 4 & 7 & & $77.1 \%$ & \\
\hline$\geq 5$ & 220 & $36.00(32.15-39.85)$ & $22.4 \%$ & \\
\hline Sites of local treatment & & & & 0.001 \\
\hline Liver & 72 & $35.43(31.05-39.82)$ & $20.3 \%$ & \\
\hline Lung & 15 & $56.77(32.62-80.92)$ & $45.7 \%$ & \\
\hline Liver and lung & 26 & & $65.6 \%$ & \\
\hline Other & 159 & $36.00(30.38-41.62)$ & $22.5 \%$ & \\
\hline Line of chemotherapy & & & & $<0.01$ \\
\hline 1 & 267 & $37.23(30.27-41.20)$ & $35.1 \%$ & \\
\hline 2 & 201 & $31.47(27.60-35.34)$ & $16.3 \%$ & \\
\hline 3 & 110 & $46.37(44.70-48.04)$ & $21.2 \%$ & \\
\hline$\geq 4$ & 46 & $46.67(32.18-56.15)$ & $38.3 \%$ & \\
\hline Pre-treatment CEA & & & & $<0.01$ \\
\hline Normal $(<5 \mathrm{ng} / \mathrm{ml})$ & 53 & $40.60(33.36-47.83)$ & $32.0 \%$ & \\
\hline Abnormal $(\geq 5 \mathrm{ng} / \mathrm{ml})$ & 142 & 34.77 (29.95-39.59) & $18.3 \%$ & \\
\hline Not reported & 77 & $42.67(32.00-53.33)$ & $35.1 \%$ & \\
\hline Pre-treatment CA 199 & & & & $<0.01$ \\
\hline Normal $(<35 \mathrm{U} / \mathrm{ml})$ & 92 & $43.93(36.40-51.47)$ & $28.3 \%$ & \\
\hline Abnormal $(\geq 35 \mathrm{U} / \mathrm{ml})$ & 89 & $31.60(23.37-39.83)$ & $9.6 \%$ & \\
\hline Not reported & 91 & $45.63(34.78-56.49)$ & $37.3 \%$ & \\
\hline Pre-treatment LDH & & & & $<0.01$ \\
\hline Normal $(<245 \mathrm{U} / \mathrm{L})$ & 133 & $39.53(34.31-44.76)$ & $25.8 \%$ & \\
\hline Abnormal $(\geq 245 \mathrm{U} / \mathrm{L})$ & 45 & $31.80(25.10-38.50)$ & $8.0 \%$ & \\
\hline Not reported & 94 & $42.67(32.09-53.24)$ & $33.6 \%$ & \\
\hline
\end{tabular}

Abbreviations: OS, overall survival; SR, survival rate;CEA,carcinoembryonic antigen;CA199,carbohydrate antigen 199; LDH,lactate dehydrogenase. 
Table 3: Predictors of survival based on multivariate analysis

\begin{tabular}{|l|l|l|l|}
\hline Factors & Number of patients & HR (95\%CI) & $\boldsymbol{P}$ \\
\hline Stage at initial diagnosis & 544 & $1.39(1.05-1.85)$ & 0.02 \\
\hline Pre-treatment CA199 $\geq 35 \mathrm{U} / \mathrm{ml}$ & 544 & $1.61(1.24-2.09)$ & $<0.01$ \\
\hline Pre-treatment LDH $\geq 245 \mathrm{U} / \mathrm{L}$ & 544 & $1.50(1.14-1.97)$ & 0.003 \\
\hline
\end{tabular}

Abbreviations: HR, hazard ratio; CA199, carbohydrate antigen 199; LDH, lactate dehydrogenase.

Table 4: Survival related to the number of prognostic factors in the local treatment and chemotherapy alone groups

\begin{tabular}{|l|l|l|l|l|l|l|}
\hline Prognostic category & Groups & OS (95\%CI) months & 2-year SR & 3-year SR & 5-year SR & $\boldsymbol{P}$ \\
\hline 0 & Local treatment & $60.03(41.52-78.55)$ & 83.7 & 61.8 & 47.9 & 0.002 \\
\hline & Chemotherapy alone & $29.07(13.98-44.15)$ & 51.2 & 29.8 & 14.9 & \\
\hline & Local treatment & $41.53(37.38-45.69)$ & 82.4 & 61.0 & 16.5 & 0.04 \\
\hline 2 & Chemotherapy alone & $25.73(19.24-32.23)$ & 50.4 & 36.7 & 26.7 & \\
\hline & Local treatment & $31.80(24.69-38.91)$ & 66.5 & 29.9 & 7.0 & 0.001 \\
\hline & Chemotherapy alone & $19.47(17.52-21.41)$ & 27.2 & 18.7 & 6.1 & 0 \\
\hline Total & Local treatment & $31.57(17.93-45.20)$ & 63.6 & 42.1 & 0 & $<0.01$ \\
\hline & Chemotherapy alone & $15.27(13.93-16.61)$ & 11.7 & 4.4 & & 0 \\
\hline & Local treatment & $37.13(33.27-41.00)$ & 76.1 & 50.8 & 22.3 & $<0.01$ \\
\hline & Chemotherapy alone & $19.47(17.85-21.09)$ & 34.8 & 22.9 & 13.4 & \\
\hline
\end{tabular}

Abbreviations; OS, overall survival; SR, survival rate.

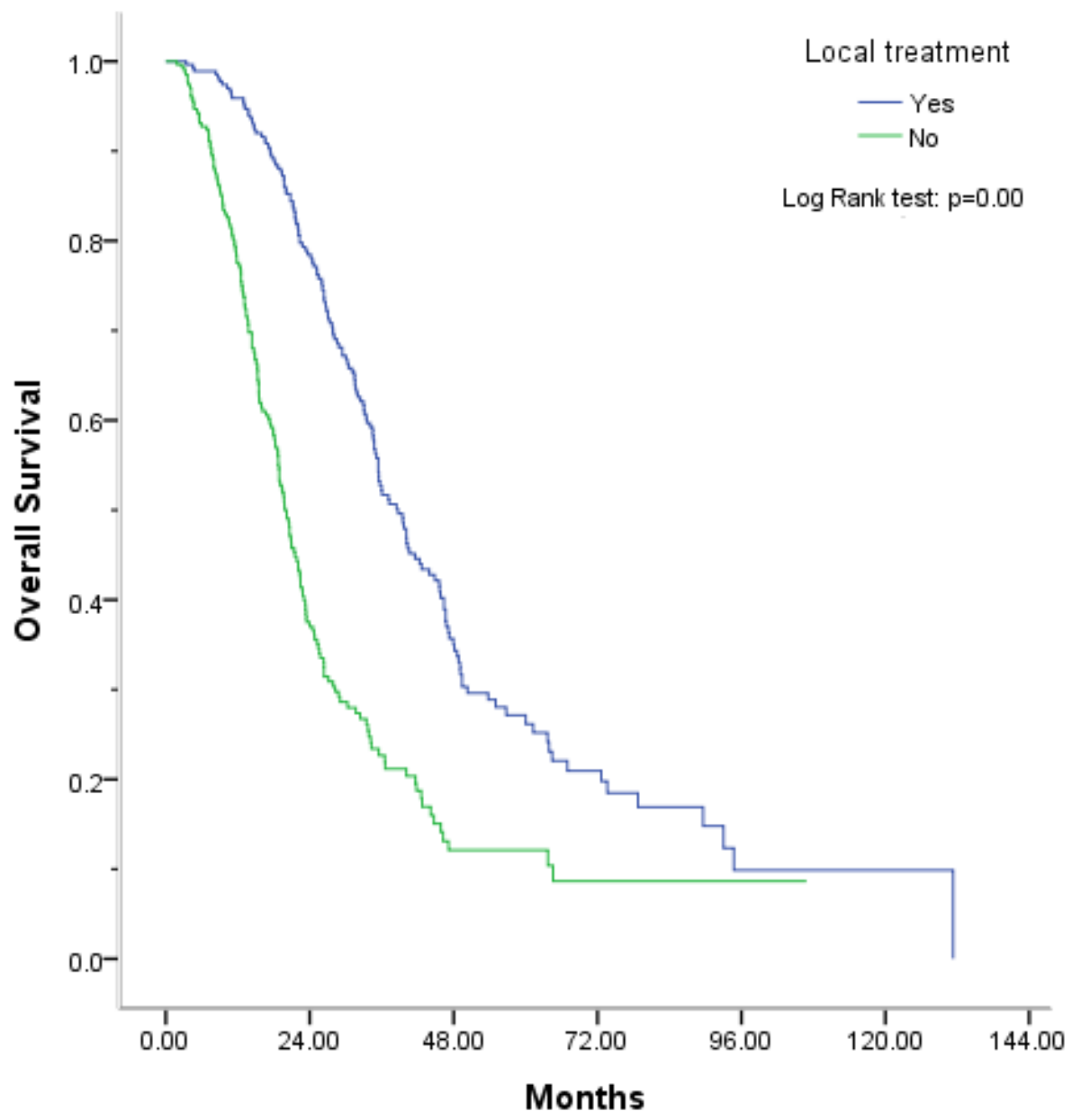

Figure 2: Overall survival benefit from adding palliative local treatment. The median OS was 38.73 months in the palliative local treatment group vs. 19.8 months in chemotherapy group $(P<0.01)$. The corresponding 5 -year survival expectancy was $26.2 \%$ and $11 \%$ in palliative local treatment group and chemotherapy alone group, respectively $(P<0.01)$. 


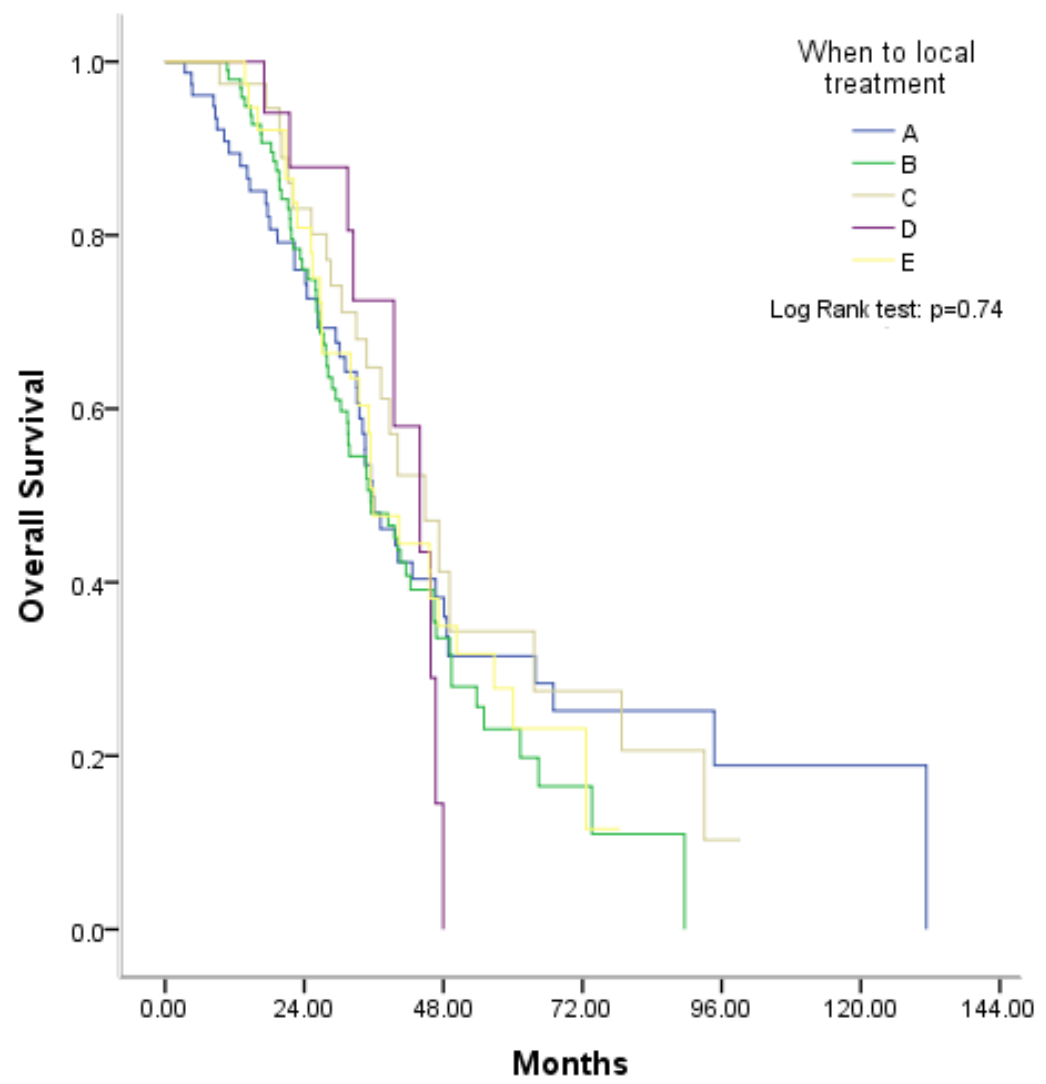

Figure 3: Effect of the timing of palliative local treatment on overall survival. A. Before the first-line therapy, B. During the first-line therapy, C. After the first-line therapy and before the second-line therapy, D. During the second-line therapy, E, After the secondline therapy.

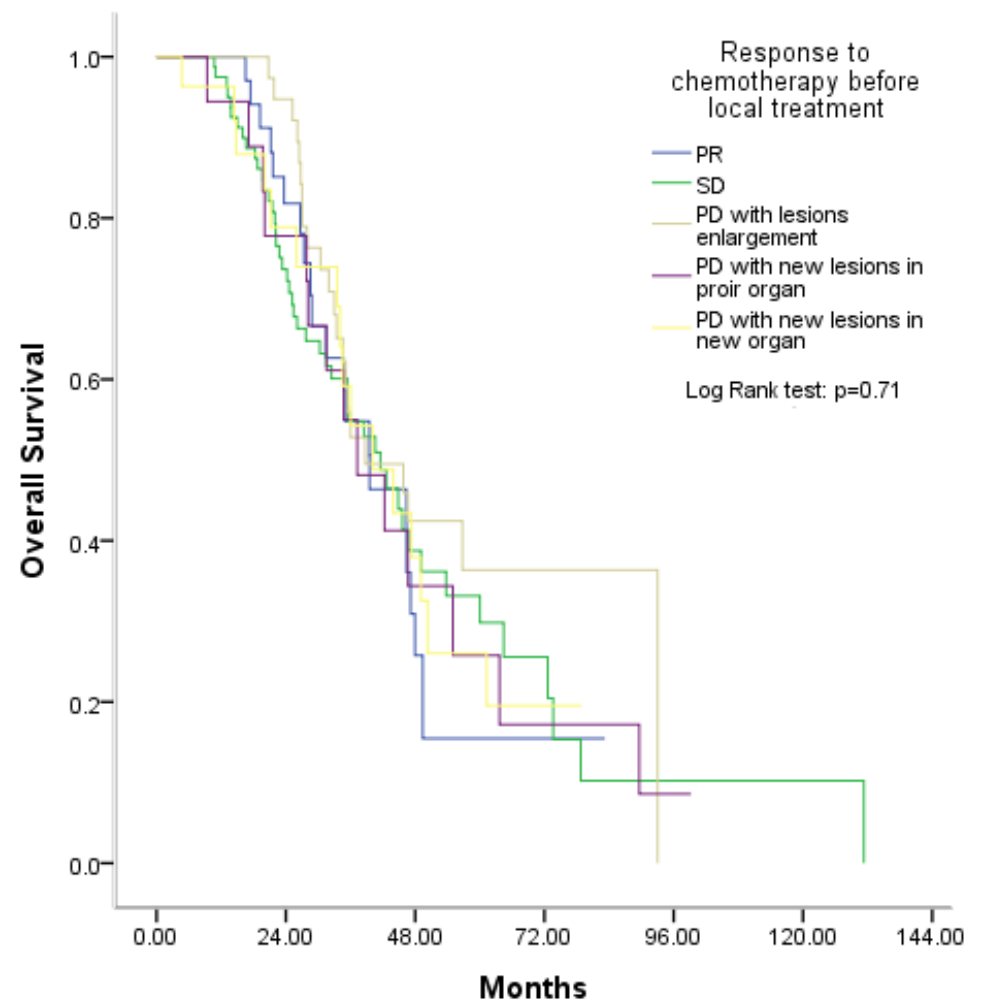

Figure 4: Overall survival after palliative local treatment was unrelated to the response to chemotherapy before palliative local treatment. $\mathrm{PR}$, partial response, $\mathrm{SD}$, stable disease, $\mathrm{PD}$, progressive disease. 
particle implantation, and radiation. The median OS was 44.87 months in the metastasectomy group and 35.43 months in non-surgery group $(P=0.05)$ (Figure 5). Patients who underwent palliative local treatment for pulmonary metastases had a median OS of 56.77 months, which was longer than those with hepatic or other metastases (median OS, 35.43 months, $P=0.01$ ) (Figure 6).

\section{DISCUSSION}

Palliative local treatment is increasingly being investigated for use with incurable metastatic lesions in mCRC because it may have survival benefit. For example, palliative thoracic radiotherapy is being used to treat advanced stage small cell lung cancer patients [16], and palliative local treatment is being administered to isolated progressing lesions in non-small cell lung cancer [17]. Using propensity score matching, we confirmed that adding palliative local treatment improves survival in patients with $\mathrm{mCRC}$.

There are three important differences between the present study and earlier ones. First, 1112 consecutive eligible patients treated between 2003 and2014 were included. To the best of our knowledge, this was the largest study to systematically explore the value of palliative local treatment in patients with unresectable mCRC. Second, patients receiving local treatment may have an expectation of a longer life, and good general condition as well as a desire for active treatment. Therefore, to minimize selection bias, this study set chemotherapy alone as the control group and used propensity score matching to make the two groups comparable [18]. Third, patients included in the present study all had highly advanced mCRC. Over $80 \%$ had more than 5 metastatic lesions, and $66.5 \%$ had two more metastatic sites. By contrast, in Ferguson et al study and $\mathrm{Hsu}$ et al study, respectively, only $30 \%$ and $33.3 \%$ of patients had extrahepatic metastases at the time RFA was administered to the hepatic lesions [14, 15].

We also explored who would most benefit from this procedure? In general, patients in poor condition or with poorer prognosis do not benefit from palliative local treatment. Our univariate and multivariate analyses indicate that patients had poorer survival if they had one or more of these factors: primary stage IV at the first diagnosis, a pre-treatment CA199 level $\geq 35 \mathrm{U} / \mathrm{ml}$ [19-21] and a pre-treatment $\mathrm{LDH} \geq 245 \mathrm{U} / \mathrm{L}$ [22-24]. When the patients were divided based on their exhibiting $0,1,2$,

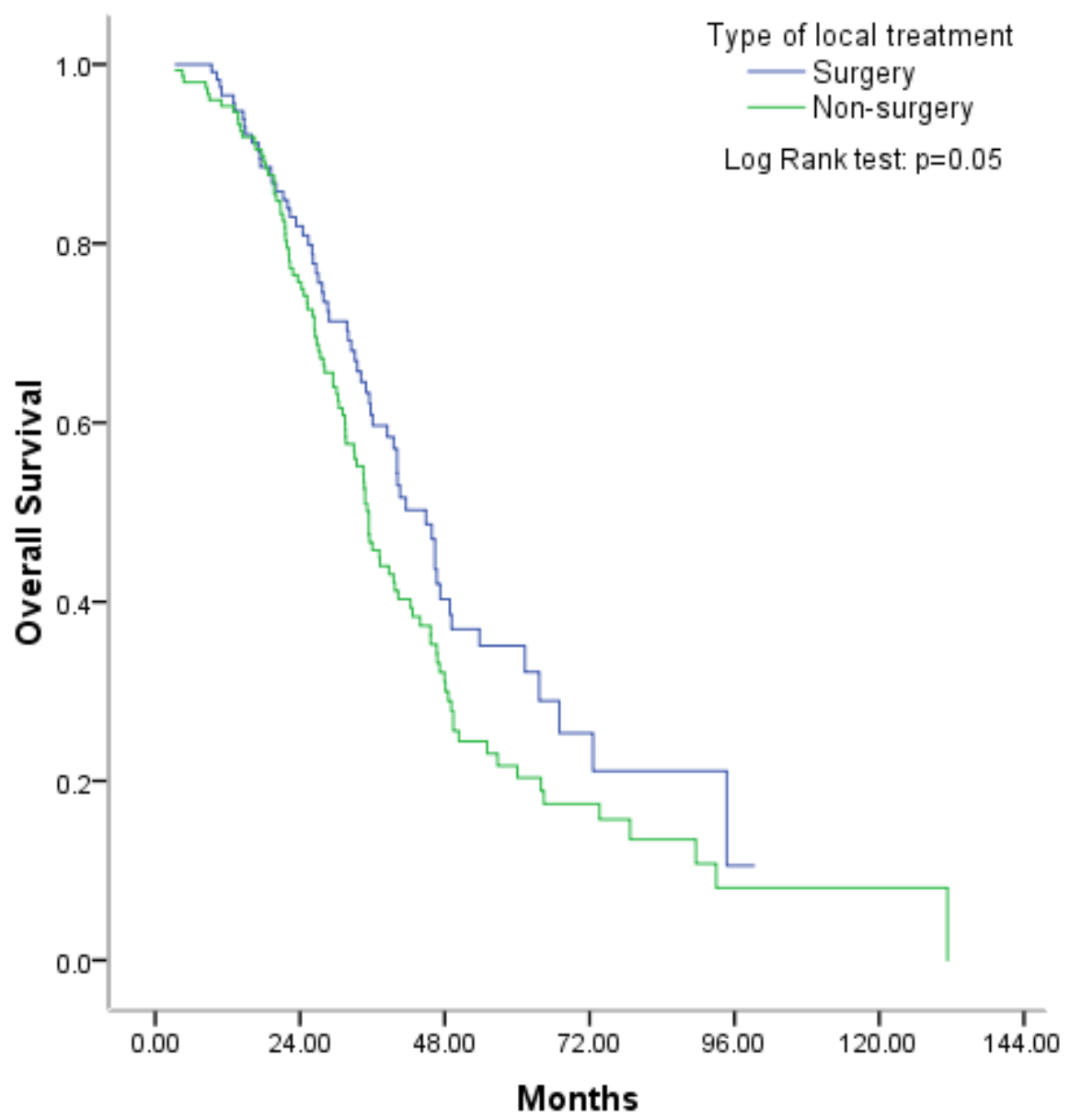

Figure 5: Overall survival was marginally better with surgical than non-surgical palliative local treatment. 
or 3 of those factors, the corresponding 5-year OS rates were $34.5 \%, 20.0 \%, 6.5 \%$ and $0 \%$, respectively. Further analysis was done to determine which patients would most benefit from palliative local treatment. Somewhat surprisingly, all four groups showed improved survival, though only patients with 0 or 1 prognostic factor had much longer survival (median OS $>40$ months). In other words, it may be appropriate for palliative local treatment to be administrated to patients with a better prognosis.

When and how to perform the palliative local treatment was also investigated, but no correlation was found between survival benefit and the timing of local treatment or the response to chemotherapy. Surgical treatment produced marginally longer survival than nonsurgical treatment. However, that result is contradicted in patients only treated with curative resection of liver metastasis after downstaging using neoadjuvant chemotherapy [1]. This reflects the nature of palliative local treatment, the aim of which is to control new lesions or reduce their potential impact on organ functions, not eradicate the tumor. On the other hand, it was not expected that palliative local treatment of pulmonary metastases would provide longer OS than treatment of other metastatic sites. Lung metastases are significantly less responsive to chemotherapy and correlate with poor survival in mCRC [25]. However, Kobayashi et al suggest that among patients with simultaneously detected metastases, metastasectomy appears to be beneficial only in patients with limited pulmonary disease [26]. In addition, Nagakura et al. reported that patients who undergo pulmonary resection alone survive longer than those who undergo hepatectomy alone, though the difference was not significant [12]. This suggests pulmonary metastases should be treated more actively in future.

There are inevitable limitations to the present study, particularly its retrospective nature, the long inclusion period, and missing data on tumor biomarkers and K-ras status. We tried our best to reduce bias by making the treatment decisions through a multidisciplinary team

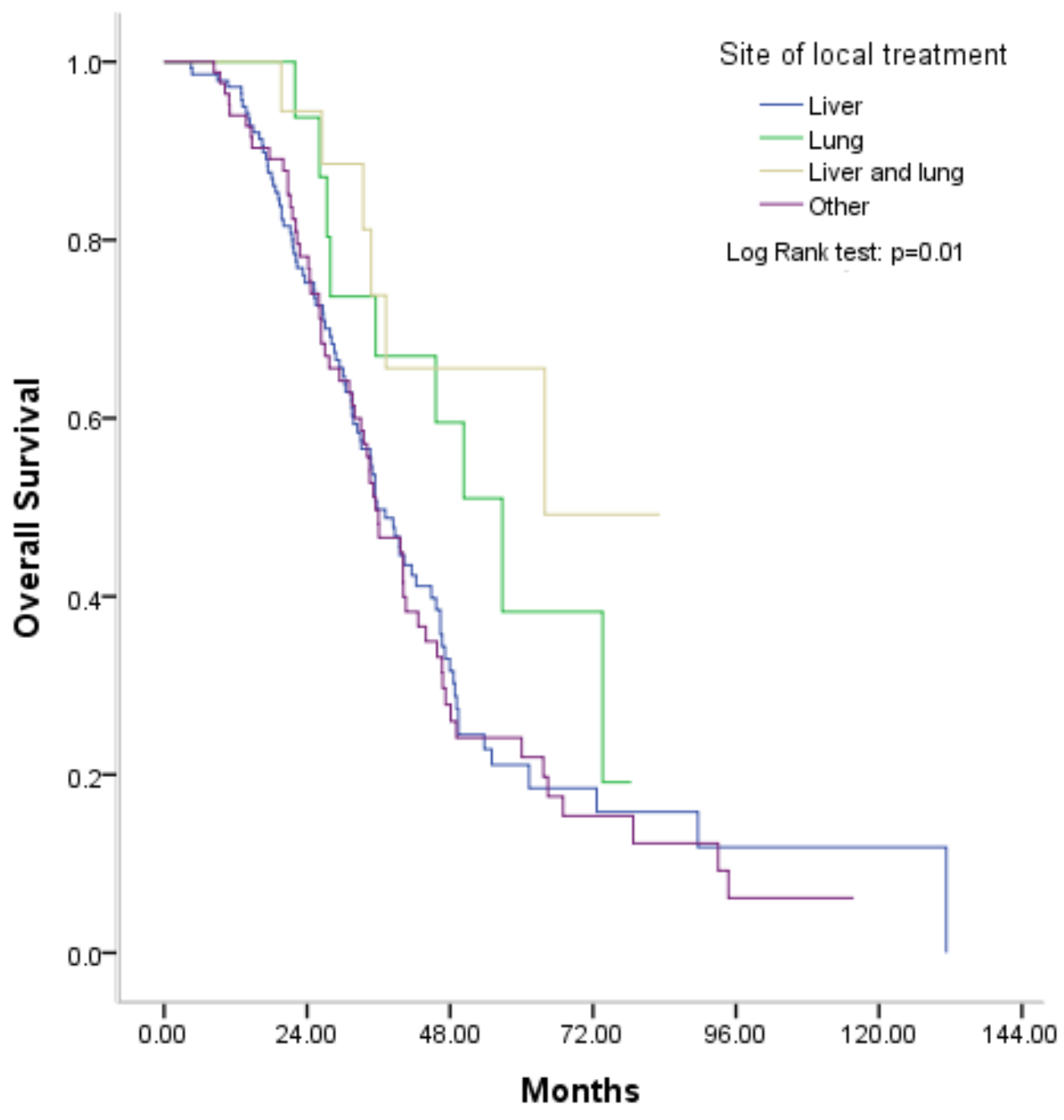

Figure 6: Overall survival was better after palliative local treatment of pulmonary metastases than other metastatic sites. 
(MDT) model [27]. But further studies will be needed to address those issues.

In sum, the present study demonstrates that a survival benefit is obtained from palliative local treatment of incurable metastatic lesions in mCRC patients. Although the survival benefit did not correlate with prognosis, patients with a better prognosis obtained the greatest benefit. Well-designed prospective clinical trials will be needed to validate these results.

\section{MATERIALS AND METHODS}

\section{Selection of the study population}

Between January 1, 2003, and September 30, 2014, consecutive patients with histologically confirmed synchronous or metachronous mCRC treated at Sun Yat-sen University Cancer Center were retrospectively reviewed. The palliative local treatment included surgery, radiofrequency ablation (RFA), percutaneous microwave coagulation therapy (PMCT), radioactive particle implantation, and radiation. Prior to palliative local treatment, the patients were expected to have (1) ECOG performance scores of 0,1 , or 2 ; (2) adequate hepatic function [bilirubin $<2.0 \mathrm{mg} / \mathrm{dl}$, transaminases levels $<$ 3 times the normal upper limit ( 5 times for patients with liver metastasis)]; (3) adequate renal function (creatinine $<1.5 \mathrm{mg} / \mathrm{dl}$ ); (4) adequate bone marrow function [absolute neutrophil count $(\mathrm{ANC})>1,500 / \mu 1$, hemoglobin $>9.0 \mathrm{~g} /$ dl, and platelets $>75,000 / \mu 1]$; (5) a life expectancy of $>3$ months. Exclusion criteria included curative local treatment, TACE, hepatic arterial infusion, non therapeutic exploratory laparotomy, emergency surgery for obstruction, hemorrhage and perforation, biliary drainage, and radiotherapy to treat bone metastasis for pain relief. The remaining patients were set as the chemotherapy alone group. The characteristics of patients in both groups were summarized in Table 1. The Institutional Review Board of the Sun Yat-sen Cancer Center approved this retrospective study.

\section{Systemic treatment}

All patients received standard palliative chemotherapy unless the patient refused. The first- and second-line regimens included oxaliplatin-containing or irinotecan-containing chemotherapy with or without target drugs. The third- and later-line therapies had no mandatory requirement. The dosage, delivery, and schedule of main therapeutic regimens were based on the principles of the NCCN guidelines (version 3, 2015).

\section{Principles of palliative local treatment}

At our center, whether palliative local treatment was administered, as well as related issues such as which lesions to treat, and the timing of intervention, was discussed by the MDT. Patients were considered suitable for palliative local treatment in the following settings: (1) liver or lung disease was predominantly limited, with or without minor additional disease; (2) most lesions were well controlled, with isolated new lesions or less than five enlarging lesions; or (3) metastatic lesions with a high risk of causing obstruction or oppression if they enlarge again, though patients had a partial disease response or stable disease during or after chemotherapy. Patients were allowed to receive one or more types or multiple administrations of palliative local treatments. Written informed consent was required before palliative local treatment.

\section{Statistical analysis}

The primary endpoint was OS. All factors likely to correlate with prognosis were evaluated. To avoid selection bias between the two groups, propensity score matching was used to choose the cases for each group. Continuous variables are presented as the mean \pm standard error, except for survival, which is presented as median (95 percent confidential interval, 95\%CI). Independentsample $\mathrm{t}$ tests were used for statistical analysis of continuous variables, and Fisher's exact test and $\chi 2$ analysis were used, as appropriate, for categorical data. All factors possibly influencing survival were evaluated using univariate and, subsequently, multivariate analyses. OS was calculated using the Kaplan-Meier method and data were compared using the log-rank test. Values of $\mathrm{P}$ less than 0.05 were considered statistically significant. Multivariate analysis using a Cox model was completed for all factors with a $\mathrm{P}$ value less than 0.05 in the univariate analysis. $\mathrm{R}$ version 2.8 was used for propensity score matching. SPSS version 18.0 was used for statistical analysis.

\section{ACKNOWLEDGMENTS}

We would like to thank staff in Sun Yat-sen University Cancer center for their working on treating patients.

\section{CONFLICTS OF INTEREST}

There are no financial or non-financial competing interests to declare in relation to this manuscript by any of the authors. 


\section{FUNDING}

This study was supported by grants from Natural Science Foundation of Guangdong, China (2015A030313010), Science and Technology Program of Guangzhou, China (1563000305) and National Natural Science Foundation of China (81272641and 81572409).

\section{REFERENCES}

1. Adam R, Delvart V, Pascal G, Valeanu A, Castaing D, Azoulay D, Giacchetti S, Paule B, Kunstlinger F, Ghémard O, Levi F, Bismuth H. Rescue surgery for unresectable colorectal liver metastases downstaged by chemotherapy: a model to predict long-term survival. Ann Surg. 2004; 240:644-657.

2. Mayo SC, Pulitano C, Marques H, Lamelas J, Wolfgang CL, de Saussure W, Choti MA, Gindrat I, Aldrighetti L, Barrosso E, Mentha G, Pawlik TM. Surgical management of patients with synchronous colorectal liver metastasis: a multicenter international analysis. J Am Coll Surg. 2013; 216:707-716.

3. Choti MA, Sitzmann JV, Tiburi MF, Sumetchotimetha W, Rangsin R, Schulick RD, Lillemoe KD, Yeo CJ, Cameron JL. Trends in long-term survival following liver resection for hepatic colorectal metastases. Ann Surg. 2002; 235:759766.

4. Fong Y, Cohen AM, Fortner JG, Enker WE, Turnbull AD, Coit DG, Marrero AM, Prasad M, Blumgart LH, Brennan MF. Liver resection for colorectal metastases. J Clin Oncol. 1997; 15:938-946.

5. Grothey A, Hedrick EE, Mass RD, Sarkar S, Suzuki S, Ramanathan RK, Hurwitz HI, Goldberg RM, Sargent DJ. Response-independent survival benefit in metastatic colorectal cancer: a comparative analysis of N9741 and AVF2107. J Clin Oncol. 2008; 26:183-189.

6. Heinemann V, von Weikersthal LF, Decker T, Kiani A, Vehling-Kaiser U, Al-Batran SE, Heintges T, Lerchenmüller C, Kahl C, Seipelt G, Kullmann F, Stauch $\mathrm{M}$, Scheithauer W, et al. FOLFIRI plus cetuximab versus FOLFIRI plus bevacizumab as first-line treatment for patients with metastatic colorectal cancer (FIRE-3): a randomised, open-label, phase 3 trial. Lancet Oncol. 2014; 15:1065-1075.

7. Fong Y, Fortner J, Sun RL, Brennan MF, Blumgart LH. Clinical score for predicting recurrence after hepatic resection for metastatic colorectal cancer: analysis of 1001 consecutive cases. Ann Surg. 1999; 230:309-318.

8. Adam R, Pascal G, Azoulay D, Tanaka K, Castaing D, Bismuth H. Liver resection for colorectal metastases: the third hepatectomy. Ann Surg. 2003; 238:871-883.

9. Mineo TC, Ambrogi V, Tonini G, Bollero P, Roselli M, Mineo D, Nofroni I. Longterm results after resection of simultaneous and sequential lung and liver metastases from colorectal carcinoma. J Am Coll Surg. 2003; 197:386-391.
10. Veltri A, Guarnieri T, Gazzera C, Busso M, Solitro F, Fora G, Racca P. Long-term outcome of radiofrequency thermal ablation (RFA) of liver metastases from colorectal cancer (CRC): size as the leading prognostic factor for survival. Radiol Med. 2012; 117:1139-1151.

11. Knudsen AR, Kannerup AS, Mortensen FV, Nielsen DT. Radiofrequency ablation of colorectal liver metastases downstaged by chemotherapy. Acta Radiol. 2009;50:716721.

12. Nagakura S, Shirai Y, Yamato Y, Yokoyama N, Suda T, Hatakeyama K. Simultaneous detection of colorectal carcinoma liver and lung metastases does not warrant resection. J Am Coll Surg. 2001; 193:153-160.

13. Berber E, Pelley R, Siperstein AE. Predictors of survival after radiofrequency thermal ablation of colorectal cancer metastases to the liver: a prospective study. J Clin Oncol. 2005; 23:1358-1364.

14. Ferguson J, Alzahrani N, Zhao J, Glenn D, Power M, Liauw W, Morris DL. Long term results of RFA to lung metastases from colorectal cancer in 157 patients. Eur J Surg Oncol. 2015; 41:690-695.

15. Hsu CW, King TM, Chang MC, Wang JH. Factors that influence survival in colorectal cancer with synchronous distant metastasis. J Chin Med Assoc. 2012; 75:370-375.

16. Slotman BJ, van Tinteren H, Praag JO, Knegjens JL, El Sharouni SY, Hatton M, Keijser A, Faivre-Finn C, Senan S. Use of thoracic radiotherapy for extensive stage small-cell lung cancer: a phase 3 randomised controlled trial. Lancet 2015; 385:36-42.

17. Yang JJ, Chen HJ, Yan HH, Zhang XC, Zhou Q, Su J, Wang Z, Xu CR, Huang YS, Wang BC, Yang XN, Zhong WZ, Nie Q, et al. Clinical modes of EGFR tyrosine kinase inhibitor failure and subsequent management in advanced non-small cell lung cancer. Lung Cancer. 2013; 79:33-39.

18. Loux TM. Randomization, matching, and propensity scores in the design and analysis of experimental studies with measured baseline covariates. Stat Med. 2015; 34:558-570.

19. Kouri M, Pyrhönen S, Kuusela P. Elevated CA19-9 as the most significant prognostic factor in advanced colorectal carcinoma. J Surg Oncol. 1992; 49:78-85.

20. Kouri M, Nordling S, Kuusela P, Pyrhönen S. Poor prognosis associated with elevated serum CA 19-9 level in advanced colorectal carcinoma, independent of DNA ploidy or SPF. Eur J Cancer. 1993; 29A:1691-1696.

21. Reiter W, Stieber P, Reuter C, Nagel D, Lau-Werner U, Lamerz R. Multivariate analysis of the prognostic value of CEA and CA 19-9 serum levels in colorectal cancer. Anticancer Res. 2000; 20:5195-5198.

22. Scartozzi M, Giampieri R, Maccaroni E, Del Prete M, Faloppi L, Bianconi M, Galizia E, Loretelli C, Belvederesi L, Bittoni A, Cascinu S. Pre-treatment lactate dehydrogenase levels as predictor of efficacy of first-line bevacizumab-based therapy in metastatic colorectal cancer patients. Br J Cancer. 2012; 106:799-804. 
23. Van Cutsem E, Bajetta E, Valle J, Köhne CH, Hecht JR, Moore M, Germond C, Berg W, Chen BL, Jalava T, Lebwohl D, Meinhardt G, Laurent D, et al. Randomized, placebo-controlled, phase III study of oxaliplatin, fluorouracil, and leucovorin with or without PTK787/ ZK 222584 in patients with previously treated metastatic colorectal adenocarcinoma. J Clin Oncol. 2011; 29:20042010.

24. Yin CX, Jiang C, Liao FX, Rong Y, Cai X, Guo G, Qiu H, Chen X, Zhang B, He W, Xia L. Initial LDH level can predict the survival benefit from bevacizumab in the firstline setting in Chinese patients with metastatic colorectal cancer. Onco Targets Ther. 2014; 7:1415-1422.
25. Assersohn L, Norman A, Cunningham D, Benepal T, Ross PJ, Oates J. Influence of metastatic site as an additional predictor for response and outcome in advanced colorectal carcinoma. Br J Cancer. 1999; 79:1800-1805.

26. Kobayashi K, Kawamura M, Ishihara T. Surgical treatment for both pulmonary and hepatic metastases from colorectal cancer. J Thorac Cardiovasc Surg 1999; 118:1090-1096.

27. Pillay B, Wootten AC, Crowe H, Corcoran N, Tran B, Bowden P, Crowe J, Costello AJ. The impact of multidisciplinary team meetings on patient assessment, management and outcomes in oncology settings: A systematic review of the literature. Cancer Treat Rev. 2016; 42:56-72. 